\title{
Influence of the degree of retting of flax fibers on the tensile properties of single fibers and short fiber/polypropylene composites
}

\author{
Nicolas Martin ${ }^{\mathrm{a}, \mathrm{c}, *}$, Nicolas Mouret ${ }^{\mathrm{c}}$, Peter Davies $^{\mathrm{b}}$, Christophe Baley $^{\mathrm{a}}$
}

\author{
a Univ. Bretagne-Sud, EA 4250, LIMATB, F-56100 Lorient, France \\ ${ }^{b}$ IFREMER, Centre de Bretagne, BP70, 29280 Plouzané, France \\ ${ }^{c}$ Van Robaeys Frères, 83, Rue Saint Michel, 59122 Killem, France \\ *: Corresponding author : Nicolas Martin, tel.: +33 297874507 ; email addresses : nicolas.martin@univ-ubs.fr ; \\ nicolas.martin.14.10.87@gmail.com \\ nmouret@vanrobaeys.fr ; peter.davies@ifremer.fr ; christophe.baley@univ-ubs.fr
}

\begin{abstract}
:
The flax quality required for composite applications is not yet well established. Retting is one of the steps that are not well defined for these applications, and is a critical parameter during flax production. In this study, the influence of the degree of retting of flax on the properties of short flax fiber/polypropylene composites has been assessed. First, the degree of retting of gradually retted flax was measured by both qualitative and quantitative experimental techniques. In addition, water sorption studies were performed. Furthermore, tensile tests were carried out on both single fiber and injected composite materials. The microstructure of the composites was analyzed by scanning electron microscopy and X-ray micro-tomography. Single fiber and composite tensile properties, as well as water sorption behavior of flax fibers, were found to depend upon the degree of retting.
\end{abstract}

\section{Highlights}

The degree of retting of gradually retted flax fibers was assessed $>$ This parameter influences the tensile properties of single fibers $>$ This also influences the tensile properties of short fiber composite materials These differences rely on the fiber properties and the microstructure of the material

Keywords: Flax fibers ; Dew-retting ; Composite materials ; Polypropylene ; Injection molding 


\section{Introduction}

Plant fibers have been used by humans for millennia for both everyday and technical applications. With the industrialization of our society, these fibers have been replaced by man-made fibers, mostly originating from fossil resources. Reduced availability of resources at affordable cost and the growing interest in sustainability have led to a renewed interest in biobased materials.

Composites reinforced with plant fibers have been the subject of numerous studies over the past two decades, and several plant fibers are of interest for composite material reinforcement (Bledzki and Gassan, 1999; Faruk et al., 2012; Summerscales et al., 2010a, 2010b). Plant fibers have many advantages compared to conventional reinforcements. These materials are renewable, have a low density compared to E-glass fibers, do not cause irritation when handled and are biodegradable under certain conditions. In addition, the production of these fibers requires less energy than that of glass fibers (Le Duigou et al., 2011). There are many species of plant fibers available all over the world, adapted to local weather conditions (Franck, 2005), which could be of interest for the development of local industries. These fibers can be found in various forms: bast fibers contained in the stems of plants e.g. flax, hemp, kenaf, ramie, jute, in the leaves e.g. abaca, sisal, or in seeds e.g cotton, capok, coir. Flax (Linum usitatissimum) is the major plant fiber cultivated in northern Europe, mainly for the textile sector. Flax fibers have excellent specific mechanical properties (Baley, 2002) and are now considered as an alternative to E-glass fibers. Studies have shown that the elastic modulus of flax mat / polylactic acid (PLA) biocomposites is in the same range as that of glass mat/polyester (Bodros et al., 2007) which can be explained by rather good fiber/matrix interface properties of this system (Le Duigou et al., 2010a, 2010b).

As far as short fiber reinforced composites are concerned, the introduction of fibers in a thermoplastic matrix increases the mechanical properties of the polymer, while still being able to use the same forming process. These materials represent half of the European glass fiber reinforced plastics market (Witten and Jahn, 2011) and are mainly used in the automotive industry as non-structural parts, e.g. interior equipment, cowls. The substitution of glass fibers by plant fibers can reduce the environmental impact of these parts (Joshi et al., 2004). It also reduces the wear of forming tools, as plant fibers cause less surface abrasion. The recycling of these materials is possible while preserving original properties (Arbelaiz et al., 2005; Bourmaud and Baley, 2007).

Several parameters influence the properties of composites reinforced by short fibers. Obviously, the intrinsic mechanical properties of the matrix and the fibers play a key role. The fiber / matrix bonding is also crucial in ensuring load transfer from the matrix to the reinforcement. This property is mainly governed by the quality of the fiber / matrix adhesion as well as the aspect ratio of the fiber reinforcement (Kelly and Tyson, 1965). This defines the critical aspect ratio of a system. Below a certain value of the aspect ratio, the contact surface between the fiber and the matrix is too weak to transfer the mechanical stress to the fibers. In this case, the shear failure mechanisms of the fiber/matrix interface are then dominant, leading to fiber/matrix debonding without fiber failure. In these short fiber thermoplastic materials manufactured by injection molding, a skin/core effect is generally observed leading to different fiber orientations. In skin areas, the fibers are oriented parallel to the flow while in core areas, the fibers are perpendicular to the flow and in the plane of the part (Vincent et al., 2005). The tensile properties of the skin part were found to be higher than those in the core zone for flax/PP composites (Bourmaud et al., 2013a). In the case of plant fibers, the state of division of the fiber bundles is an important additional parameter compared to man-made fibers. It is worth mentioning that the single fibers are arranged in bundles in the plant and the extraction and division of those bundles remain incomplete even after decortication. 
A series of chemical treatments have been developed to improve the fiber / matrix adhesion of flax / PP composites by increasing their compatibility. For example, silane, alkaline and acetylation treatments have been studied (Bledzki, 2008; Bledzki et al., 2004; Cantero et al., 2003; Elsabbagh et al., 2009; Hornsby et al., 1997; Zafeiropoulos et al., 2002a, 2002b). The use of maleic anhydride grafted polypropylene (MA-PP) in amounts less than $5 \%$ of the mass of matrix has been shown to provide the best composite tensile properties (Arbelaiz et al., 2005; Cantero et al., 2003). By single fiber pull-out test, Stamboulis et al. (1999) showed that a dew-retted flax/PP system exhibited an apparent interfacial shear strength (IFFS) of 11 $\mathrm{MPa}$. The same value was found for the dew-retted flax/ MA-PP (5\%) system. By single fiber fragmentation tests (SFFT), Awal et al (2011) showed that IFSS was higher for flax / MA-PP (13.9 MPa) compared to flax / PP (4.5 MPa). With the same method Van den Oever et al (1998) found an IFSS of $8 \mathrm{MPa}$ for the flax/PP system and $12 \mathrm{MPa}$ for the flax/MA-PP system.

In Northern Europe, flax cultivation lasts about 100 days, the sowing takes place at the end of March, then flowering usually occurs at the beginning of June. When the plants are mature in early July, the stems are pulled from the ground and left on the field in swaths for the dewretting period, before being harvested and decorticated by the scutching process. During retting, the flax stems are colonized by fungi enhanced by the combined action of moisture and heat (Brown and Sharma, 1984). These fungi release several enzymes that degrade pectins (Meijer et al., 1995; Rosemberg and De França, 1967). As a result epidermis, cortical parenchyma and middle lamella are degraded and fibers bundles split (Akin et al., 1996). Calcium pectates are considered to be retting resistant and are the limiting factor of retting (Sharma, 1988). These complex pectins are present in the cell junctions between single fiber in the bundles (Andème-Onzighi et al., 2000; Jauneau et al., 1992). The retting stage can last from 3 weeks to a month and a half depending on the mass of straw per surface unit and weather conditions (humidity and temperature). This practice leads to easier fiber decortication and a better use for textile applications (Pallesen, 1996) as dew retted fibers have less residual shives and cortical tissues (Meijer et al., 1995) and are thinner (Kessler et al., 1998; Sharma and Faughey, 1999). Therefore retting determines the state of division of the fiber bundle and the surface quality of the latter.

Retting is highly weather dependent, hence it is difficult to master the retting progress. Indeed, it is tempting to further ret the stems when the retting degree is not sufficiently advanced but this could led to over retting and partial degradation of fibers by cellulases enzymes (Brown and Sharma, 1984) in the case of continuously wet weather. For practical and economical reasons, it is hardly possible to harvest and store wet flax straw (Pallesen, 1996) because of mold development during storage. Excessive retting also lowers the yields, as degradation of the material occurs (Pallesen, 1996). There are alternative methods to field retting. Water retting is not an option due to water pollution by substances created by the anaerobic degradation of the plants, while enzyme retting is a more complex and costly method. However, retting is essential to achieve efficient decortication of the stems. Consequently a ratio has to be found between crop yield, security of supply, cost and quality of fibers.

The degree of retting can be assessed by a biochemical approach by measuring the decrease in the amount of pectins (Meijer et al., 1995) or sugar analysis (Mooney et al., 2001) which is a precise but rather time consuming technique. The textile industry uses industrial devices such as airflow (Kessler et al., 1998; Meijer et al., 1995; Sharma et al., 1999), or a shirley analyser (Meijer et al., 1995; Van de Weyenberg et al., 2003). A number of other methods are described in the literature such as thermo-gravimetric analysis (TGA) (Sharma and Faughey, 1999; Sharma et al., 1999; Van de Velde and Baetens, 2001) or near Infra-red spectroscopy (NIR) (Di Candilo et al., 2000; Kessler et al., 1998). However there is no standardized technique that is fast, inexpensive and can be used in industry to assess the degree of retting of flax fibers. 
Several organoleptic methods are used to assess the quality of flax: length, fineness (visual assessment of the division of fiber bundles), color, strength (manual test). The flax quality is dependent on the quality of the incoming stems and a quality assessment can only be made at the end of fiber production. These methods determine the target application: textile, papers, ropes, and the market value. The color and fineness are the most discriminating criteria for the valuation of flax fibers in the textile industry, whereas the color of the fibers as such is not a criterion for the production of composite materials, and division of the fiber bundles initiated by retting and scutching, can be extended during the forming processes used for the production of compounds (extrusion) and then during injection molding of composites (Arbelaiz et al., 2005; Oksman et al., 2009).

The aim of this work is to evaluate the importance of the retting step of flax fibers for composite material reinforcement. First, the degree of retting of flax was evaluated by various methods: spectrocolorimetry, scanning electron microscopy (SEM), thermo gravimetric analysis, and biochemical extraction of surface components of the fiber bundles were performed. Tensile properties of single fibers were studied. In a second step, short flax fiber/PP composites were processed by injection molding and the morphology of the reinforcements was examined after processing. The microstructure of these materials was assessed by SEM observation and X-ray micro tomography. Finally, tensile properties of the composites were measured and compared to theoretical properties determined by micromechanical models.

\section{Materials and methods}

\subsection{Raw materials}

Flax plants of the Alizée variety were grown in France (Nord-Pas de Calais) in 2011 and were provided by Van Robaeys Frères $₫$ (Killem, France). Flax stems were pulled at the end of June and dew-retted in the field. Fig.1 shows the weather conditions during the retting period and Table 1 gives the dates of collection of the samples. The daily average temperature was the sum of daily minimum temperature and daily maximum temperature divided by two. Six sets of samples were collected during the retting period, named R1 to R6. During the period of retting, there was little rainfall between the uprooting and the 14th day of retting $(3 \mathrm{~mm})$ and then $30 \mathrm{~mm}$ between the 14th day and last sample collection.

Sample R6 is considered to be well retted and corresponds to the standard quality for linen textiles, whereas samples R1 to R4 are regarded as under retted. One has to bear in mind that retting time is not established theoretically, but relies on the experience of the farmers. This particular retting time R6 is valid for the field and weather conditions of the year of culture. It was faster compared to other years due to a low flax straw yield (5052 kg.ha-1) whereas the average yield measured for this region was $6925 \mathrm{~kg}$.ha-1 between 2000 and 2009. A minimum retting time is sought in order to avoid the risk of over retting and fiber degradation. After harvesting, the stems were stored in a dry building. The flax stems were then scutched, with the same machine settings for each set of samples, and scutched technical fibers were subsequently cut to a $3 \mathrm{~mm}$ length for composite manufacturing.

The average elementary fiber diameter of the batch was measured for R1, R3 and R6 by optical microscopy. A few fiber bundles were embedded in an epoxy resin and the cross section of the bundles was polished. The cross sectional diameters of 250 single fibers were measured. As flax fibers exhibit a polygonal section, the longest and smallest distances were recorded and values were averaged. For clarity, this value is named batch average diameter in the text. 
The polymer used as a matrix for composite manufacturing is polypropylene (PP) reference PPC 10642 provided by Total Petrochemicals. In order to improve the compatibility between the matrix and the reinforcements, $4 \%$ by weight of maleic anhydride grafted PP (MA-PP), Orevac CA100 supplied by Arkema, was added to the PP matrix.

\subsection{Assessment of the degree of retting}

Various techniques have been evaluated in order to assess the degree of retting of the samples. All the measurements were performed on 3 samples to indicate the scatter in values.

\subsubsection{Spectrocolorimetry}

The tests were performed on fiber bundles using a Minolta spectrophotometer. The results are presented in the CIELAB 1976color system according to ISO 11664 for the D65illuminant with a viewing angle of $10^{\circ}$. The luminance $(L)$ parameter defines the brightness from 0 to 100 , $a$ and $b$ are two chromatic parameters ranging from -60 to +60 , representing red, green, yellow and blue.

\subsubsection{Scanning Electron Microscopy}

The samples were sputter coated with a thin gold layer by sputtering using an Edwards Scancoat Six apparatus before being examined with a Jeol JSM 6460LV scanning electron microscope. For fiber bundles surface observation, the samples were bonded onto a carbon tape allowing observation of the length. Before coating of the short fiber composite materials, samples were embedded in an epoxy matrix and polished to obtain the desired thickness.

\subsubsection{Thermogravimetric Analysis}

Samples were kept at a temperature of $23^{\circ} \mathrm{C}$ and $50 \%$ relative humidity for 72 hours prior to analysis. The experiments were carried out on a Mettler Toledo TGA / DSC 1. The samples (50mg) were heated in air from $25^{\circ} \mathrm{C}$ to $600^{\circ} \mathrm{C}$ at the rate of $3^{\circ} \mathrm{C} \cdot \mathrm{min}^{-1}$. The mass variation as a function of temperature was recorded.

\subsubsection{Extraction of surface components of fiber bundles}

The extractions were carried out according to methods described in the literature (Goubet et al., 1995; Jauneau et al., 1992). Samples were first washed with distilled water at room temperature to remove dust, before being washed 3 times with boiling distilled water for $1 \mathrm{~h}$. Subsequently, samples were washed with an ethylene-diamine-tetraacetic acid (EDTA) solution $(0.25 \%)$ for $1 \mathrm{~h}$ then rinsed in boiling distilled water for 1 hour twice. Between each step, the fibers were dried for $12 \mathrm{~h}$ at $80^{\circ} \mathrm{C}$ and weighed.

\subsubsection{Fibers moisture uptake test}

The samples were stored at $23^{\circ} \mathrm{C}$ and $50 \%$ relative humidity $(\mathrm{RH})$ and were weighed before being enclosed in glass vessels above saturated salt solutions. $\mathrm{NaCl}$ solutions, $\mathrm{KCl}$ solutions and distilled water with activities respectively of $0.76,0.84$ (Weast, 1981) and 1 were used. Samples were left in these atmospheres until masses reached a constant value.

\subsection{Tensile test on single fibers}

Single flax fibers were hand extracted from fiber bundles selected in the central zone of the stem in order to limit the scatter in mechanical properties. Charlet et al. (2007) have shown that the tensile properties of single flax fibers are different from stem root to stem tip, and 
exhibit a maximum value in the central area of the stem. Single fibers were then bonded onto a paper frame before being clamped in an MTS Synergie RT/1000 tensile machine equipped with a $2 \mathrm{~N}$ load cell. Tensile tests were carried out according to the AFNOR XP T-501-2 standard at controlled temperature $\left(23^{\circ} \mathrm{C}\right)$ and humidity $(50 \%)$. Samples were kept at least 48 hours under these conditions prior to the test.

The gauge length was $10 \mathrm{~mm}$, crosshead displacement speed was $1 \mathrm{~mm} \cdot \mathrm{min}^{-1}$. Calculated values of Young's modulus and failure strain take into account the compliance of the tensile machine. The mean apparent diameters measured at three different points along a single fiber were used for these calculations. Approximately 50 fibers were tested for each condition. The results were analyzed statistically using the Student's t test.

\subsection{Composites manufacturing}

Composites materials were manufactured in 3 steps. First, the materials were mixed by extrusion, then pelletized and finally molded by injection.

Flax fiber bundles and MA-PP were dried for 24 hours at $50^{\circ} \mathrm{C}$ prior to extrusion with PP. The extrusion was carried out in a single screw extruder at $20 \mathrm{rpm}$ with a screw and die temperature of $190^{\circ} \mathrm{C}$. Fiber bundles were added in order to achieve a $20 \%$ volume fraction. Compounded pellets were dried for $24 \mathrm{~h}$ at $50^{\circ} \mathrm{C}$ before injection molding. Injection of the composite tensile specimens was carried out at $190^{\circ} \mathrm{C}$ in a Battenfeld press with a dog bone shaped mold. The mold temperature was $30^{\circ} \mathrm{C}$. The residence time from pellet entering the machine to part demoulding was around $300 \mathrm{~s}$.

Density measurements were performed on tensile specimens according to ISO 1183-1 using the immersion method with $1 \mathrm{~g}$ samples and ethanol as a fluid. Fibre volume fraction was estimated using the classical rule of mixture considering a value of $1.53 \mathrm{~g}_{\mathrm{cm}} \mathrm{cm}^{-3}$ for fiber

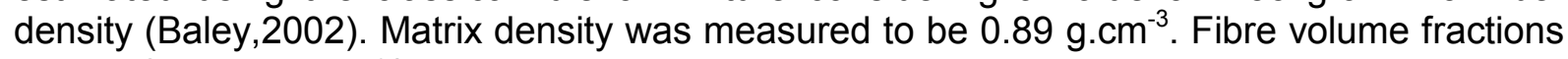
ranged from 19 to $20 \%$.

\subsection{Extraction and morphology of reinforcements}

Prior to optical observation, the reinforcements were extracted from the composite materials using hot o-xylene (Oksman et al., 2009). Morphologies of around 250 reinforcements were measured using a binocular microscope after cutting, after extrusion and after injection molding of the composites. The results were analyzed statistically using the Student's t test.

\subsection{X-Ray Micro-Tomography}

$X$ ray tomography is a non-destructive technique developed originally for medical applications, which enables a three-dimensional image of a sample to be constructed using the measurement of attenuation of X-rays (Hounsfield, 1973). This technique allows the core of samples to be examined without damaging it, offering the possibility to precisely scan areas of interest avoiding the sectioning and polishing of samples. This has been used in the past to study the structure of injected short glass fiber / polyamide reinforced composites (Bernasconi et al., 2008), of PLA/flax mat/balsa sandwich (Le Duigou et al., 2012) and of miscanthus / PP or miscanthus / PLA composites (Ragoubi et al., 2012). X-ray microtomography was used here to study the microstructure of flax/PP composites. Measurements were made on a GE Phoenix V-TOM-X240 high-resolution microfocus computed tomography system. Analyses were performed on approximately $10 \times 4 \times 20 \mathrm{~mm}^{3}$ volume samples. The linear resolution was $20 \mu \mathrm{m}$. Porosity content measurements were 
carried out assuming a lower limit of 8 voxel, in order to avoid noise in calculations. MyVGL2.0 data analysis software was used to extract images. A recent study using the same tomography equipment as here showed examples of its use for high performance sandwich material studies (Davies et al., 2011).

\subsection{Tensile testing of composites}

Tensile tests were performed on dog-bone tensile specimens according to ISO-527-2 on a MTS Synergie RT/1000 tensile machine. The capacity of the load cell was $10 \mathrm{kN}$ and a 25 $\mathrm{mm}$ nominal length extensometer was used. The crosshead displacement speed was 1 $\mathrm{mm} \cdot \mathrm{min}^{-1}$. At least 5 samples were tested and Young's modulus, maximum strength and failure strain were averaged. The Young's modulus was obtained by calculating the slope of the tensile curve in the strain range: $\varepsilon_{1}=0.05 \%$ to $\varepsilon_{2}=0.25 \%$.

\section{Results and discussions}

For some analyses, results were only presented for R1, R3 and R6.

\subsection{Assessment of the degree of retting}

Fig. 2 shows a photo of the 6 sets of samples. A significant colour difference was observed from unretted to retted samples. The color of R1 fibers, which were retted one day, was light green-yellow whereas the color of R6 fibers, which were retted 19 days was dark grey. This kind of color change was reported previously for dew-retted flax (Pallesen, 1996). Table 2 presents the results of the colorimetric measurements. There was a decrease in luminance $(L)$ with the degree of retting. Parameter $b$ first increased between R1 and R2 and then started to decrease significantly from R3. Parameter a increased from R1 to R3, then there is a drop with R4 and R5 and a small increase with R6. The changes in a and b between R1 and R3 are related to the yellow to orange transition and then from R4 to R6, the red $(+a)$ and the yellow $(+b)$ components decrease corresponding to orange to gray color transition as is visible in Fig.2. The transition from yellow colour of unretted flax to the dark grey colour of dew retted flax might be attributed to the colonization of fungi during retting. The various fungi gradually cover the surface of the stem and lead to the characterictic colors of dewretted fiber. Even if the color of composite materials is not a criterion in this work, it is important to note that spectrocolorimetry can easily assess the influence of retting on fiber color, avoiding inaccurate organoleptic assessment. This technique could be useful for industrial assessment of retting as a quick, cheap and quite accurate characterization.

Fig. 3 a) shows the bundle organization of flax fibers in the stems. In the flax stem, single fibers are stuck together by a thin middle lamella in the form of bundles of 20 to 40 unitary fibers, these bundles are located in the phloem and surrounded by the cortical parenchyma at the periphery of the stem, between epidermis and xylem which is a woody core (Akin et al., 1996). Pectins are the main constituents of the middle lamella. Fig. $3 \mathrm{~b}$ ) shows the structure of a single flax fiber which is composed of cellulose, hemicelluloses, pectins, waxes and a certain amount of water. It is structured in two cell walls, a primary cell wall and a secondary cell wall containing three layers S1, S2 and S3, the most important being the S2 layer whose thickness is $5-15 \mu \mathrm{m}$. This layer consists mainly of cellulose embedded in a matrix of hemicellulose and pectins (Morvan et al., 2003).

Fig. 4 shows SEM images of the fiber bundles for R1 R3 and R6 batch. In our case, single fibers were still gathered in the form of bundles but retting has changed their surface. The R1 sample surfaces exhibit a layer that entirely covers the surface of the bundles, preventing the 
observation of the cell walls. The R3 sample is also covered with a layer but the surface of some fibers is visible. For the R6 sample, the fibers remain grouped in bundles but are more divided, cortical tissues have been removed and a part of middle lamellae has been degraded. Some fiber bundles are split in single fibers. Fig. 4. (f) highlights the surface of the primary cell wall of R6 single fibers. As expected, SEM shows that retting frees the fiber bundles from cortex tissues.

Table 3 presents the mass losses of samples after chemical treatments by boiling water and EDTA $0.25 \%$ boiling solutions. These treatments were used to assess the quantity of materials remaining at the fiber bundle surface after the retting step by measuring the mass loss after chemical treatments. The first distilled water washing $(A)$ enables weakly bonded elements (dust, shives, soil) to be removed from the surface. This first mass loss is quite high and probably not relevant, as the fibers were hand shaken for 30 seconds or so in distilled water and fibers could have been lost. The $(A)$ washed fiber final weight is used for the reference for mass loss calculations. The boiling water treatment $(B)$ is used to extract the bundle surface compounds and a part of the primary cell walls of single fibers (Bourmaud et al., 2010). Treatment with EDTA solution (C) can chelate calcium ions linked to pectic chains and extract the components of the primary cell wall (Goubet et al., 1995; Morvan et al., 2003). These components are the ones expected to be degraded by the retting step. The work of Bourmaud et al. (2010) reported a weight loss of $15 \%$ after room temperature and a boiling water washing for poorly retted fibers. The removed sugars were glucose, galactose, homogalacturonan and rhamnogalacturonan of type I.

The mass loss during the combined treatment decreases with increasing degree of retting of fibers, which confirms the cleaning of fibers and removal of cortical parenchyma and middle lamellae. Low retted fibers contain a higher proportion of surface components. This result is consistent with SEM examination as a layer of cortical tissues was found at the surface of R1 and R3 fiber bundles. In our extraction, these remaining materials might be removed by the EDTA treatment. The mass loss for higher retted samples indicates that even after a good retting step, a certain amount of materials still remained at the fiber bundle surface.

Table 4 shows mass loss measured by TGA. Fig. 5 shows the mass loss and rate of degradation (derivative) curves as a function of temperature for different levels of retting. This technique was first used by Sharma and Kernaghan (1988) to evaluate the thermal behavior of flax, and thereafter to evaluate the degree of retting (Sharma and Faughey, 1999; Sharma et al., 1999; Van de Velde and Baetens, 2001), the fineness of flax (Faughey et al., 2000), or the effect of a water treatment (Bourmaud et al., 2010).

Three mass losses are observed. The first mass loss corresponds to the loss of water, the second loss between 200 and $400{ }^{\circ} \mathrm{C}$ corresponds to the degradation of pectins, hemicelluloses and cellulose (Sharma and Kernaghan, 1988), and the third corresponds to the degradation of non-polysaccharidic substances such as phenols (Sharma et al., 1996). According to Van de Velde and Baetens (2001), polysaccharides composing the fibers could be depolymerized between $200^{\circ} \mathrm{C}$ and $400^{\circ} \mathrm{C}$, forming by-products themselves degraded at higher temperatures. Remaining mass after stabilization corresponds to the ash content and decreases with retting. According to Ghaffari et al. (2007) citrus pectins degrade at $200^{\circ}$ C. There are very few studies in the literature concerning pectins from flax. During retting, pectins are degraded increasing the proportion of cellulose and hemicelluloses, which explains the increase of the second weight loss with increasing degree of retting. This increase in second weight loss is consistent with previously published studies (Sharma and Faughey, 1999; Sharma et al., 1999; Van de Velde and Kiekens, 2001). Degradation of the low retted fibers occurs at lower temperature, this can be explained by the early degradation of the compounds present at the surface of low retted samples, such as retting residues, cortex materials and middle lamellae. For the same storage conditions, the percentage of water contained in fibers was found to be identical (see Table 4). Retting does not have any 
influence on the water content of fibers under these conditions $(50 \% \mathrm{RH})$. Measured water contents are within the range of values found in the literature (Baley et al., 2005).

Fig. 6 shows the results of water uptake of fibers for different relative humidities. The fibers (R1, R3,R6) were kept for 8 days at $50 \%$ RH before testing but were not oven dried to avoid modification of the cell walls, this could change their sensitivity to water (Baley et al., 2005). For ease of reading, the initial water content, measured by TGA, is added to presented values. There is a higher mass gain for R1 and R3 compared to R6, indicating a higher uptake for less retted fibers. The difference increases with relative humidity. This is in agreement with the work of Alix et al. (2012), who reported a higher water uptake for 1-week retted fibers compared to 6 - week retted fibers. The water content is $32 \%$ for R1 and $22 \%$ for $\mathrm{R} 6$ at $100 \% \mathrm{RH}$. This latter value is consistent with the work of Hill et al. 2009 who report a water content of $20 \%$ at $95 \% \mathrm{RH}$ for dew-retted fibers. Stamboulis et al. (2000) reported a water content of $42.6 \%$ at $100 \% \mathrm{RH}$ for green flax. A strong influence of the degree of retting on water absorption was highlighted here. In plant fibers the water is bonded to the $-\mathrm{OH}$ groups at the surface and within the fibers, especially to pectins (Baley et al. 2005). Hence, the difference of moisture absorption between retted and unretted fibers could be related to the removal of pectic material mainly coming from middle lamella during retting. This type of control could be used in an industrial context to measure the degree of retting.

\subsection{Influence of the degree of retting on the tensile properties of single fibers}

Fig. 6 and Table 6 show the results of single fiber tensile tests. The values of Young's modulus, strength and strain at break are reported. The average diameter of single fibers from each batch are given and the average diameter of the tensile tested fibers are also reported for comparison. The mean diameter of fibers selected for tensile testing is slightly larger than the diameter of the batch for R1, R3 and R6 $(P<0.05)$. This could be due to hand extraction of fibers. One has to keep in mind that single fiber handling is a delicate operation. It is not possible to choose fibers randomly as larger objects are generally detected by the human eye. Selected fibers were considered to be representative of the batch. The diameter of fibers increases with increasing degree of retting. Average diameter of R6 is higher than $\mathrm{R} 1(\mathrm{P}<0.001)$. This can be observed either on tensile test fibers or on batch fibers. Diameters would have been expected to decrease, as a consequence of the removal of material by retting. Bourmaud et al. (2010) carried out water treatments on poorly retted fibers and also noticed an increase in the mean fiber diameter, which could be related to the release of the entanglement of the pectic network within the primary wall of fibers after the removal of middle lamella enriched in calcium-HGA

The mechanical properties of single fibers are influenced by the degree of retting. Higher retting results in higher Young's modulus $(P<0.001)$ and strength $(P<0.01)$. There is little variation in the failure strains. The scatter in values tends to decrease with increasing retting degree. One has to bear in mind the sources of uncertainty when measuring natural fiber diameters. Unlike manmade fibers, they exhibit a polygonal cross section (5-6-7 faces) often uneven, and have a hollow lumen in the core. This cross section area varies along the fiber itself and from fiber to fiber (Charlet et al., 2010). Optical microscopy measurement transverse to the fiber axis gives an apparent diameter, which can be different depending on the viewing side. This apparent diameter is generally used for cross sectional area calculations assuming a circular cross section. The use of a failure zone diameter after tensile tests doesn't change the values of calculated strength and Young's modulus (Charlet et al., 2010). A consistent way to evaluate real cross sectional area would be to embed tested fibers in mounting resin and measure the failure cross sectional area after polishing, this was done on fiber bundles tensile test specimens by Hu et al.(2010). Recent work by Virk et al. (2010) aiming to overcome the uncertainties arising from the use of strength and Young's modulus, suggests the use of strain at break as a design criterion for biocomposites. 
Other studies suggest modifying the rule of mixtures to take into account the variability of plant fibers mechanical properties. Virk et al. (2012) proposed a fiber area correction factor in the rule of mixtures accounting for the difference between apparent cross section area of jute technical fiber and the true cross sectional areas measured on around 800 fibers. As far as strength is concerned, failure is governed by defects present on the fibers known as kink bands (Baley, 2004), so single fibers would be likely to fail in the weakest zone but not necessarily where the smallest area is.

Table 6 shows previously published tensile properties of single fibers. The studies were made on the same tensile machine and under the same environmental conditions. The tensile properties of single fibers studied in this work are in the same range and the scatter in strength and Young's modulus is lower compared to literature values (mainly R6).

Previously published studies attempting to assess the effect of retting on the tensile properties of single fibers show a lack of consensus. Van de Weyenberg (2005) showed a higher Weibull tensile strength for half-retted flax compared to green flax. This difference was justified by a higher presence of weak areas in the fiber and a greater amount of non-retted substances such as pectins, hemicelluloses and impurity. Van de Velde and Baetens (2001) studied tensile properties of flax fiber bundles for different degrees of retting, the tensile strength was lower for the first degree of retting, but the tensile behavior of a bundle is different from the tensile behavior of a single fiber. Alix et al. (2012) reported equivalent tensile properties between green and dew-retted technical flax fibers. The work of Pillin et al. (2011) compared the influence of two degrees of retting on the tensile properties of single fibers from linseed flax, mean values of strength and Young's modulus were higher for better retted samples but were considered to be equal as standard deviations were large.

\subsection{Composite properties}

\subsubsection{Evolution of fiber morphology during the composites processing}

To understand the differences in tensile properties, fiber morphology was studied as aspect ratio of the reinforcement is an important parameter for load transfer between fibers and matrix.

Table 7 shows the length, diameter and aspect ratio of the raw fibers, fibers after compounding by extrusion, and fibers after injection molding of the tensile specimens. For raw fibers, the mean fiber length was close to $3 \mathrm{~mm}$ for the 3 batches, highlighting the accuracy of the cutting process. The mean diameters of the fibers indicate that these are mostly in the form of fiber bundles for the three samples, the average diameter of a single fiber being approximately $14 \mu \mathrm{m}$. Retting weakened middle lamellae but bundles were not further divided. This conclusion can also be made based on SEM observations. The average diameter of the bundles was not affected by the degree of retting. Aspect ratio was not found to be different between the three samples $(P>0.05)$. The morphology of the raw fibers was not affected by the degree of retting.

After compounding, there was a decrease in fiber lengths, diameters and aspect ratio compared to the raw fibers due to the splitting of fiber bundles during extrusion. The average fiber lengths and the mean diameters are smaller for more highly retted fibers. The reduction of length from low retted to high retted fibers might be explained by the easier splitting of fiber bundles into ultimate single fibers. The higher aspect ratio for $R 6(P<0.01)$ indicates better splitting of fiber bundles during extrusion. Distributions of aspect ratios, lengths and diameters were reduced compared to raw fibers. 
After injection molding, there was a reduction in the length and diameter of the fibers for R1, R3 and R6, compared to extrusion, indicating that the injection step further splits the fiber bundles. The values of aspect ratio are consistent with previously reported values for injected flax/PP materials (Arbelaiz et al., 2005). The diameter values indicate that reinforcements were partly in the form of bundles for R1 and R3 whereas measurements indicate a diameter of $20.5 \mu \mathrm{m}$ for R6 which is close to the average single fiber diameter of the batch, and show that most of the reinforcements were in the form of single fibers, with few bundles. This reveals a strong splitting of fiber bundles. The average diameter is smaller and aspect ratio is higher for R6 $(\mathrm{P}<0.01)$ indicating a better division of the fiber bundles in the composite material. There is an influence of the degree of retting on the splitting of fiber bundles and hence, the aspect ratio is increased.

\subsubsection{Composite materials microstructure}

Composite materials microstructure was studied to see whether the degree of retting of flax has an effect on the organization of fibers within the polymer. A skin-core effect was reported by Bourmaud et al. (2013) for dew-retted flax/PP injected composites. SEM analyses were carried out on skin and core of R1 and R6 tensile specimens. Fig. 7 b) shows the analyzed area. Fig. 7 a) exhibits the skin and core of R1 and R6 samples. A skin-core effect was visible for the 2 samples. Fig. $7 \mathrm{c}$ ) is a 3D diagram represents the typical skin-core orientation of the fibers in an injection molded part. In the skin zone the fibers were almost aligned parallel to the flow whereas in the core zone, the fibers are parallel to the flow close to the edges of the tensile specimen and then show a progressive orientation from the edges towards the center, where the fibers are perpendicular to the flow and in the plane of the tensile specimen. The R1 sample exhibits an important quantity of fiber bundles either in skin or core whereas R6 sample exhibit less fiber bundles and an important number of single fibers. This is in agreement with fiber diameter measurements. This highlights the better ability of well retted fibers to split during the composites processing. SEM high resolution pictures allow assessment of the overall orientation of fibers, and splitting behavior of the fibers induced by the degree of retting. This is only available for a particular plane and so information about the volume microstructure of the material is somewhat limited.

X-ray Micro-tomography analysis was carried out on composites reinforced with R1, R3 and R6 samples to study composite materials volume microstructure. The analysis was performed on the central area of dog bone shaped tensile specimens. Fig. 8 shows a comparison between skin and core of R6 short fiber / PP composites. Only the R6 sample is presented as similar orientation of fibers is found on R1, R3 and R6. Sample R6 shows less fiber bundles compared to R1 and R3 even if the resolution does not allow observation of the single fibers. This highlights the greater bundle splitting after extrusion and injection molding for higher retting degree. This observation correlates well with the diameter measurements performed after fiber bundle extraction. Fig. 9 shows a 3D view of the composite material tensile specimens for R1, R3 and R6. The three samples exhibit a low porosity content which decreases with the degree of retting, estimated as respectively $0.3 \%$, 0.2 and $0.07 \%$ of the analyzed volume for R1, R3 and R6 samples. Those voids were mainly located in the core zone in a plane parallel to the flow direction. This technique gives lower resolution data than SEM data but allows a scan to be made of the entire sample thickness and assessment of the porosity content of the samples.

\subsubsection{Composite tensile properties}

Fig. 10 shows the tensile properties of composites made of PP matrix and the different qualities of fibers. The mechanical properties obtained for flax / PP composites are higher compared to the virgin matrix for all grades of fiber, highlighting the reinforcement capacity of 
flax fibers. Strain at break decreases with the introduction of fibers. The tensile properties of composites are improved with a higher degree of retting of flax fibers which follows the same trend as single fiber properties. The Young's modulus and tensile strength are increased despite the random orientation of fibers in the tensile specimens. Strain at break is decreased compared to virgin PP, but the degree of retting does not affect the strain at break of the composite materials. The scatter of the tensile properties is low.

Van de Weyenberg et al. (2003) studied the influence of the degree of retting of flax on the mechanical properties of unidirectional flax/epoxy composites and showed that the better the retting degree of the fibres, the better the composite properties are.

The increase of the mechanical properties of the short flax fibers/PP composites might originate from several factors. The increase in single fiber intrinsic tensile properties enhances the mechanical properties of the composite materials. The surface, morphology and orientation of the reinforcements will also play a key role. SEM examination of fiber bundle surfaces indicated cleaner and smoother surfaces. Moreover, biochemical extractions have indicated that fewer residues are found on the surface of fiber bundles. The surface of the individual fibers is therefore more easily accessible to the matrix, promoting cohesion. In addition, shives and cortical residues remaining after scutching are less present.

As a high degree of retting enables easier splitting of the fiber bundles during fiber / matrix extrusion and injection molding, the division of composite reinforcements is more important for a high degree of retting, which results in smaller fiber bundle diameters and a higher aspect ratio. Hence, the interface area between fiber and matrix is increased.

X-Ray microtomography showed that the samples contain a relatively low amount of porosity. These defects were mostly located in the core of samples where the orientation of the fibers is parallel to the loading axis during tensile tests. This region is damaged first during tensile tests and the presence of porosities might enhance this damage.

In order to examine how fiber properties transfer to injected composites it is interesting to evaluate micromechanics models. Knowing the elastic properties of the fibers, the matrix and the fiber volume fraction, it is possible to estimate the stiffness of a ply reinforced with short fiber randomly dispersed in the plane of lamination. The approach is based on the analogy between a composite with randomly distributed reinforcements in the plane and a quasiisotropic laminate of the type [0/90/ \pm 45$]$.

The input data are given in Table 5 (single fiber tensile properties) and Table 7 (aspect ratio).

Micromechanics models must account for:

- Highly anisotropic fiber properties,

- Fiber orientation,

- Fiber aspect ratio,

- Fiber volume fraction.

It should be emphasized that few studies have performed such modelling for natural fiber composites using the measured properties of the fibers. It should also be noted that one of the sources of uncertainty in such modeling is the value of the fiber transverse modulus. Bourmaud et al. (2009) have obtained, by nanoindentation, a transverse modulus of $4.98 \pm$ 
1.52 GPa and $3.85 \pm 0.87 \mathrm{GPa}$ respectively for hemp and sisal fibers. Baley (2002) have estimated the transverse modulus of flax fiber to be around $8 \mathrm{GPa}$ by using micromechanical expressions (Baley et al., 2006). This latter value (8 GPa) will be used in the models presented here.

The longitudinal modulus $E_{L}$ and the transverse modulus $E_{T}$ for a ply reinforced by short unidirectional fibers are given by equations (2) and (3) proposed by Halpin-Tsaï models (Halpin and Kardos, 1976):

$$
\begin{array}{r}
\frac{\mathrm{M}}{\mathrm{M}_{\mathrm{m}}}=\frac{1+\xi \cdot \eta \cdot \mathrm{V}_{\mathrm{f}}}{1-\eta \cdot \mathrm{V}_{\mathrm{f}}} \\
\eta=\frac{\frac{M_{f}}{M_{n}}-1}{\frac{M_{f}}{M_{m}}+\xi}
\end{array}
$$

where $M=E_{L}$ or $E_{T}, M_{f}=E_{f l}$ or $E_{f t}$ and $m, f, L$ and $T$ correspond to matrix, fiber, longitudinal and transverse. $V_{f}$ is the fiber volume fraction and $\xi$ the form factor. For the longitudinal modulus, $\xi=2 \mathrm{~L} / \mathrm{d}$ where $\mathrm{L} / \mathrm{d}$ is the fiber aspect ratio. For the transverse modulus $\mathrm{E}_{\mathrm{T}}$, satisfactory results have been obtained with $\xi=2$ (Gibson, 2011).

Knowing the longitudinal and transversal stiffness of a ply reinforced by unidirectional fibres, the Young's modulus of a ply reinforced by randomly dispersed fibers (hypothesis considered here in order to simplify the model) is then given by the following expression (Gibson, 2011):

$$
E_{\text {mat }}=\frac{3}{8} E_{L}+\frac{5}{8} E_{T}
$$

where $E_{L}$ is the longitudinal modulus and $E_{T}$ the transverse modulus of the unidirectional ply, determined from expressions (2) and (3). The assumptions used in these models are a random in-plane fiber distribution, the absence of skin/core distribution effects, and a homogeneous distribution of individual fibers (no bundles). The fiber volume fraction used for the calculation was $20.3 \%$. Table 8 shows the results.

Other models exists in the literature. For example, the work of Summerscales et al. (2011) reported the use of a fiber diameter distribution factor taking into account the evolution of the Young's modulus of jute technical fibers as a function of fiber diameter, in order to modify the rule of mixtures. Their results showed a good correlation between measured and predicted values for jute fiber unidirectional composites.

Given the various simplifying assumptions, our results indicates a reasonable correlation between tests and predictions, the $\xi$ values chosen here, which are those generally used in the literature for man-made fiber composites, provide a good prediction of plant fiber composite mechanical properties. The relatively low fiber aspect ratios limit the transfer of fiber properties to the matrix, higher stiffness could be obtained with a higher aspect ratio. 


\section{Conclusion}

In this study, the influence of retting on the properties of single flax fibers and short flax fibers /polypropylene composites has been studied.

Several methods were used to characterize the effect of retting on fiber properties and measure the degree of retting of fibers. The visible color change from yellow to grey has been highlighted and normalized using spectrocolorimetry. Degradation of the cortical parenchyma and middle lamella was highlighted by scanning electron microscopy and biochemical extraction of the fiber bundle surface components. TGA measurements have shown the difference in thermal degradation of fibers and provide an additional measurement of the degree of retting.

Water sorption studies indicated a higher water uptake for low retted fibers. The measurement of water sorption behavior of composite materials for different degrees of retting of fibers would be of interest in the future.

The tensile properties of single fibers increased with the degree of retting for both Young's modulus and strength at break. Nevertheless, this increase in tensile properties is complex. The reasons why the degree of retting influences the tensile properties of flax fibers are not clearly identified, removal of low performance material clearly contributes but the sampling procedure may also introduce statistical bias.

The mechanical properties of short fibers reinforced composites were increased with a high degree of retting. Intrinsic tensile properties, surface and aspect ratio of fibers play a key role. A high degree of retting enables easier splitting of the fiber bundles during fiber / matrix extrusion and injection molding. The division of composite reinforcements is more important for a high degree of retting, which results in smaller fiber bundle diameters and a higher aspect ratio. The morphological analysis of the composites revealed a skin/core effect. The samples contained a relatively low amount of porosity which decreased with increasing degree of retting. Defects were mostly located in the core of samples.

For yarn manufacturing, the textile industry seeks thin and well separated fiber bundles in order to process thin yarns. These selection criteria are, to some extent, applicable for selecting fibers for short fiber composite applications. This paper highlights the importance of measuring the degree of retting of flax fibers in order to optimize reinforcement quality for composites. The mechanisms that induce an improvement in single fiber tensile properties have to be further explored.

\section{Acknowledgements}

The authors would like to thank the national association of research and technologies (ANRT) for funding for a joint PhD between Van Robaeys Frères S.A, The University of South Brittany, and Ifremer. 


\section{References}

Akin, D.E., Gamble, G.R., Morrison III, W.H., Rigsby, L.L., Dodd, R.B., 1996. Chemical and Structural Analysis of Fibre and Core Tissues from Flax. J. Sci. Food Agric. 72, 155165.

Alix, S., Lebrun, L., Marais, S., Philippe, E., Bourmaud, A., Baley, C., Morvan, C., 2012. Pectinase treatments on technical fibres of flax: Effects on water sorption and mechanical properties. Carbohydrate Polymers 87, 177-185.

Andème-Onzighi, C., Girault, R., His, I., Morvan, C., Driouich, A., 2000. Immunocytochemical characterization of early-developing flax fiber cell walls. Protoplasma 213, 235-245.

Arbelaiz, A., Fernandez, B., Cantero, G., Llano-Ponte, R., Valea, A., Mondragon, I., 2005. Mechanical properties of flax fibre/polypropylene composites. Influence of fibre/matrix modification and glass fibre hybridization. Compos. Part A Appl. Sci. Manuf. 36, 1637-1644.

Awal, A., Cescutti, G., Ghosh, S.B., Müssig, J., 2011. Interfacial studies of natural fibre/polypropylene composites using single fibre fragmentation test (SFFT). Compos. Part A Appl. Sci. Manuf. 42, 50-56.

Baley, C., 2002. Analysis of the flax fibres tensile behaviour and analysis of the tensile stiffness increase. Compos. Part A Appl. Sci. Manuf. 33, 939-948.

Baley, C., 2004. Influence of kink bands on the tensile strength of flax fibers. J. Mater. Sci. 39, 331-334.

Baley, C., Morvan, C., Grohens, Y., 2005. Influence of the Absorbed Water on the Tensile Strength of Flax Fibers. Macromol. Symp. 222, 195-202.

Baley, C., Perrot, Y., Busnel, F., Guezenoc, H., Davies, P., 2006. Transverse tensile behaviour of unidirectional plies reinforced with flax fibres. Mater. Lett. 60, 29842987.

Bernasconi, A., Cosmi, F., Dreossi, D., 2008. Local anisotropy analysis of injection moulded fibre reinforced polymer composites. Compos. Sci. Technol. 68, 2574-2581.

Bledzki, A.K., 2008. The effects of acetylation on properties of flax fibre and its polypropylene composites. Express Polym. Lett. 2, 413-422.

Bledzki, A.K., Fink, H.-P., Specht, K., 2004. Unidirectional hemp and flax EP- and PPcomposites: Influence of defined fiber treatments. J. Appl. Polym. Sci. 93, 21502156.

Bledzki, A.K., Gassan, J., 1999. Composites reinforced with cellulose based fibres. Prog. Polym. Sci. 24, 221-274.

Bodros, E., Pillin, I., Montrelay, N., Baley, C., 2007. Could biopolymers reinforced by randomly scattered flax fibre be used in structural applications? Compos. Sci. Technol. 67, 462-470.

Bourmaud, A., Ausias, G., Lebrun, G., Tachon, M.-L., Baley, C., 2013a. Observation of the structure of a composite polypropylene/flax and damage mechanisms under stress. Ind. Crops. Prod. 43, 225-236.

Bourmaud, A., Baley, C., 2007. Investigations on the recycling of hemp and sisal fibre reinforced polypropylene composites. Polym. Degrad. Stab. 92, 1034-1045.

Bourmaud, A., Baley, C., 2009. Rigidity analysis of polypropylene/vegetal fibre composites after recycling. Polym. Degrad. Stab. 94, 297-305.

Bourmaud, A., Morvan, C., Baley, C., 2010. Importance of fiber preparation to optimize the surface and mechanical properties of unitary flax fiber. Ind. Crops. Prod. 32, 662667.

Bourmaud, A., Morvan, C., Bouali, A., Placet, V., Perré, P., Baley, C., 2013b. Relationships between micro-fibrillar angle, mechanical properties and biochemical composition of flax fibers. Ind. Crops. Prod. 44, 343-351.

Brown, A.E., Sharma, H. s. s., 1984. Production of polysaccharide-degrading enzymes by saprophytic fungi from glyphosate-treated flax and their involvement in retting. Ann. Appl. Biol. 105, 65-74. 
Cantero, G., Arbelaiz, A., Llano-Ponte, R., Mondragon, I., 2003. Effects of fibre treatment on wettability and mechanical behaviour of flax/polypropylene composites. Compos. Sci. Technol. 63, 1247-1254.

Charlet, K., Baley, C., Morvan, C., Jernot, J.P., Gomina, M., Bréard, J., 2007. Characteristics of Hermès flax fibres as a function of their location in the stem and properties of the derived unidirectional composites. Compos. Part A Appl. Sci. Manuf. 38, 1912-1921.

Charlet, K., Jernot, J.-P., Breard, J., Gomina, M., 2010. Scattering of morphological and mechanical properties of flax fibres. Ind. Crops. Prod. 32, 220-224.

Davies, P., Choqueuse, D., Bourbouze, G., 2011. Micro-Tomography to Study Highperformance Sandwich Structures. J. Sandw. Struct. Mater. 13, 7-21.

Di Candilo, M., Ranalli, P., Bozzi, C., Focher, B., Mastromei, G., 2000. Preliminary results of tests facing with the controlled retting of hemp. Ind. Crops. Prod. 11, 197-203.

Elsabbagh, A., Steuernagel, L., Ziegmann, G., 2009. Effect of fiber/matrix chemical modification on the mechanical properties and water absorption of extruded flax/polypropylene composite. J. Appl. Polym. Sci. 111, 2279-2289.

Faruk, O., Bledzki, A.K., Fink, H.-P., Sain, M., 2012. Biocomposites reinforced with natural fibers: 2000-2010. Prog. Polym. Sci. 37, 1552-1596.

Faughey, G.J., Sharma, S.S., McCall, R.D., 2000. Determining fiber fineness in flax using derivative thermogravimetric analysis, scanning electron microscopy, and airflow methods. J. Appl. Polym. Sci. 75, 508-514.

Franck, R.R., 2005. Bast And Other Plant Fibres. CRC Press.

Ghaffari, A., Navaee, K., Oskoui, M., Bayati, K., Rafiee-Tehrani, M., 2007. Preparation and characterization of free mixed-film of pectin/chitosan/Eudragit $\AA$ RS intended for sigmoidal drug delivery. European Journal of Pharmaceutics and Biopharmaceutics 67, 175-186.

Gibson, R.F., 2011. Principles of Composite Material Mechanics, Third Edition, 3rd ed. CRC Press.

Goubet, F., Bourlard, T., Girault, R., Alexandre, C., Vandevelde, M.-C., Morvan, C., 1995. Structural features of galactans from flax fibres. Carbohydr. Polym. 27, 221-227.

Halpin, J.C., Kardos, J.L., 1976. The Halpin-Tsai equations: A review. Polym. Eng. Sci. 16, 344-352.

Hill, C.A.S., Norton, A., Newman, G., 2009. The water vapor sorption behavior of natural fibers. J. Appl. Polym. Sci. 112, 1524-1537.

Hornsby, P.R., Hinrichsen, E., Tarverdi, K., 1997. Preparation and properties of polypropylene composites reinforced with wheat and flax straw fibres: Part II Analysis of composite microstructure and mechanical properties. J. Mater. Sci. 32, 1009-1015.

Hounsfield, G.N., 1973. Computerized transverse axial scanning (tomography): Part 1. Description of system. Br. J. Radiol. 46, 1016-1022.

Hu, W., Ton-That, M., Perrin-Sarazin, F., Denault, J., 2010. An improved method for single fiber tensile test of natural fibers. Polym. Eng. Sci. 50, 819-825.

Jauneau, A., Morvan, C., Lefebvre, F., Demarty, M., Ripoll, C., Thellier, M., 1992. Differential Extractability of Calcium and Pectic Substances in Different Wall Regions of Epicotyl Cells in Young Flax Plants. J. Histochem. Cytochem. 40, 1183-1189.

Joshi, S.., Drzal, L.., Mohanty, A.., Arora, S., 2004. Are natural fiber composites environmentally superior to glass fiber reinforced composites? Compos. Part A Appl. Sci. Manuf. 35, 371-376.

Kelly, A., Tyson, W.R., 1965. Tensile properties of fibre-reinforced metals: Copper/tungsten and copper/molybdenum. J. Mech. Phys. Solids. 13, 329-350.

Kessler, R.W., Becker, U., Kohler, R., Goth, B., 1998. Steam explosion of flax - a superior technique for upgrading fibre value. Biomass Bioenergy 14, 237-249.

Le Duigou, A., Davies, P., Baley, C., 2010a. Interfacial bonding of Flax fibre/Poly(I-lactide) bio-composites. Compos. Sci. Technol. 70, 231-239.

Le Duigou, A., Davies, P., Baley, C., 2010b. Macroscopic analysis of interfacial properties of flax/PLLA biocomposites. Compos. Sci. Technol. 70, 1612-1620. 
Le Duigou, A., Davies, P., Baley, C., 2011. Environmental Impact Analysis of the Production of Flax Fibres to be Used as Composite Material Reinforcement. J. Biobased Mater. Bioenergy 5, 153-165.

Le Duigou, A., Deux, J.-M., Davies, P., Baley, C., 2012. PLLA/Flax Mat/Balsa BioSandwich-Environmental Impact and Simplified Life Cycle Analysis. Appl Compos Mater 19, 363-378.

Meijer, W.J.M., Vertregt, N., Rutgers, B., Van de Waart, M., 1995. The pectin content as a measure of the retting and rettability of flax. Ind. Crops. Prod. 4, 273-284.

Mooney, C., Stolle-Smits, T., Schols, H., De Jong, E., 2001. Analysis of retted and non retted flax fibres by chemical and enzymatic means. J. Biotechnol. 89, 205-216.

Morvan, C., Andème-Onzighi, C., Girault, R., Himmelsbach, D.S., Driouich, A., Akin, D.E., 2003. Building flax fibres: more than one brick in the walls. Plant Physiol. Biochem. 41, 935-944.

Oksman, K., Mathew, A.P., Långström, R., Nyström, B., Joseph, K., 2009. The influence of fibre microstructure on fibre breakage and mechanical properties of natural fibre reinforced polypropylene. Compos. Sci. Technol. 69, 1847-1853.

Pallesen, B.E., 1996. The quality of combine-harvested fibre flax for industrials purposes depends on the degree of retting. Ind. Crops. Prod. 5, 65-78.

Pillin, I., Kervoelen, A., Bourmaud, A., Goimard, J., Montrelay, N., Baley, C., 2011. Could oleaginous flax fibers be used as reinforcement for polymers? Ind. Crops. Prod. 34, 1556-1563.

Ragoubi, M., George, B., Molina, S., Bienaimé, D., Merlin, A., Hiver, J.-M., Dahoun, A., 2012. Effect of corona discharge treatment on mechanical and thermal properties of composites based on miscanthus fibres and polylactic acid or polypropylene matrix. Compos. Part A Appl. Sci. Manuf. 43, 675-685.

Rosemberg, J.A., De França, F.P., 1967. Importance of Galacturonic Acid in Controlling the Retting of Flax. Appl. Microbiol. 15, 484-486.

Roussière, F., Baley, C., Godard, G., Burr, D., 2012. Compressive and Tensile Behaviours of PLLA Matrix Composites Reinforced with Randomly Dispersed Flax Fibres. Appl Compos Mater 19, 171-188.

Sharma, H.S.S., 1988. Chemical retting of flax using chelating compounds. Ann. Appl. Biol. 113, 159-165.

Sharma, H.S.S., Faughey, G., Lyons, G., 1999. Comparison of physical, chemical, and thermal characteristics of water-, dew-, and enzyme-retted flax fibers. J. Appl. Polym. Sci. 74, 139-143.

Sharma, H.S.S., Faughey, G., McCall, D., 1996. Effect of Sample Preparation and Heating Rate on the Differential Thermogravimetric Analysis of Flax Fibres. J. Text. Inst. 87, 249-257.

Sharma, H.S.S., Faughey, G.J., 1999. Comparison of subjective and objective methods to assess flax straw cultivars and fibre quality after dew-retting. Ann. Appl. Biol. 135, 495-501.

Sharma, H.S.S., Kernaghan, K., 1988. Thermogravimetric analysis of flax fibres. Thermochim. Acta 132, 101-109.

Stamboulis, A., Baillie, C., Schulz, E., 1999. Interfacial characterisation of flax fibrethermoplastic polymer composites by the pull-out test. Die angew. Makromol. Chem 272, 117-120.

Summerscales, J., Dissanayake, N., Virk, A., Hall, W., 2010a. A review of bast fibres and their composites. Part 2 - Composites. Compos. Part A Appl. Sci. Manuf. 41, 13361344.

Summerscales, J., Dissanayake, N.P.J., Virk, A.S., Hall, W., 2010b. A review of bast fibres and their composites. Part 1 - Fibres as reinforcements. Compos. Part A Appl. Sci. Manuf. 41, 1329-1335.

Summerscales, J., Hall, W., Virk, A.S., 2011. A fibre diameter distribution factor (FDDF) for natural fibre composites. J. Mater. Sci. 46, 5876-5880. 
Van de Velde, K., Baetens, E., 2001. Thermal and Mechanical Properties of Flax Fibres as Potential Composite Reinforcement. Macromol. Mater. Eng. 286, 342-349.

Van de Velde, K., Kiekens, P., 2001. Thermoplastic pultrusion of natural fibre reinforced composites. Compos. Struct. 54, 355-360.

Van de Weyenberg I., 2005. Flax Fibres as a Reinforcement for Epoxy Composites (PhD Thesis). University of Leuven.

Van de Weyenberg, I., Ivens, J., De Coster, A., Kino, B., Baetens, E., Verpoest, I., 2003. Influence of processing and chemical treatment of flax fibres on their composites. Compos. Sci. Technol. 63, 1241-1246.

Van Den Oever, M.J.A., Bos, H.L., 1998. Critical fibre length and apparent interfacial shear strength of single flax fibre polypropylene composites. Adv Compos Lett 7, 81-85.

Vincent, M., Giroud, T., Clarke, A., Eberhardt, C., 2005. Description and modeling of fiber orientation in injection molding of fiber reinforced thermoplastics. Polym. 46, 67196725.

Virk, A.S., Hall, W., Summerscales, J., 2010. Failure strain as the key design criterion for fracture of natural fibre composites. Compos. Sci. Technol. 70, 995-999.

Virk, A.S., Hall, W., Summerscales, J., 2012. Modulus and strength prediction for natural fibre composites. Mater. Sci. Technol. 28, 864-871.

Weast, R.C. (Ed.), 1981. CRC Handbook of Chemistry and Physics 62nd Edition 1981-1982. CRC Press, Inc.

Witten, E., Jahn, B., 2011. Composites Market Report 2011: Market developments, trends, challenges and opportunities. European Composites Industry Association (EuCIA).

Zafeiropoulos, N.., Baillie, C.., Hodgkinson, J.., 2002a. Engineering and characterisation of the interface in flax fibre/polypropylene composite materials. Part II. The effect of surface treatments on the interface. Compos. Part A Appl. Sci. Manuf. 33, 11851190.

Zafeiropoulos, N.., Williams, D.., Baillie, C.., Matthews, F.., 2002b. Engineering and characterisation of the interface in flax fibre/polypropylene composite materials. Part I. Development and investigation of surface treatments. Compos. Part A Appl. Sci. Manuf. 33, 1083-1093.

Tables

Table 1 Identification of samples collected and corresponding retting time.

\begin{tabular}{ccccccc}
\hline Batch name & R1 & R2 & R3 & R4 & R5 & R6 \\
\hline $\begin{array}{c}\text { Retting time } \\
\text { (days) }\end{array}$ & 1 & 5 & 9 & 14 & 16 & 19 \\
\hline
\end{tabular}

Table 2 Colour values measured using the CIELAB system for each sample.

\begin{tabular}{ccccccc}
\hline Sample & R1 & R2 & R3 & R4 & R5 & R6 \\
\hline L & 70.6 & 67.6 & 62.4 & 52.2 & 50.1 & 50.8 \\
a & 3.6 & 4.9 & 5.0 & 3.4 & 2.0 & 2.6 \\
b & 24.9 & 25.6 & 24.1 & 18.7 & 13.4 & 13.0 \\
\hline
\end{tabular}


Table 3 Quantity of material loss after boiling water and boiling EDTA solution treatment.

\begin{tabular}{lcccc}
\hline & \multicolumn{3}{c}{ Mass loss (\%) } \\
& $\mathrm{A}: \mathrm{H}_{2} \mathrm{O} 23^{\circ} \mathrm{C}$ & $\mathrm{B}: \mathrm{H}_{2} \mathrm{O} 100^{\circ} \mathrm{C}$ & $\mathrm{C}:$ EDTA $100^{\circ} \mathrm{C}$ & $\mathrm{B}+\mathrm{C}$ \\
\hline $\mathrm{R} 1$ & $16,2 \pm 1,4$ & $5.8 \pm 2.8$ & $14.9 \pm 4.1$ & $20.6 \pm 5$ \\
$\mathrm{R} 2$ & $12,3 \pm 0,3$ & $6.9 \pm 0.2$ & $9.4 \pm 0.4$ & $16.2 \pm 0.5$ \\
$\mathrm{R} 3$ & $16,2 \pm 1,4$ & $7.5 \pm 0.3$ & $8.3 \pm 0.1$ & $15.76 \pm 0.4$ \\
$\mathrm{R} 4$ & $17,9 \pm 1,4$ & $6.1 \pm 0.7$ & $6.6 \pm 0.6$ & $12.7 \pm 0.9$ \\
$\mathrm{R} 5$ & $16,1 \pm 0,9$ & $4.4 \pm 0.6$ & $5.7 \pm 0.3$ & $10.2 \pm 0.7$ \\
$\mathrm{R} 6$ & $6,2 \pm 1,7$ & $4.8 \pm 0.4$ & $5.6 \pm 1.6$ & $10.5 \pm 1.4$ \\
\hline
\end{tabular}

Table 4 Results of thermogravimetric analysis.

\begin{tabular}{|c|c|c|c|c|c|c|c|}
\hline Sample & $1^{\text {st }}$ loss $(\%)$ & $\mathrm{T}\left({ }^{\circ} \mathrm{C}\right)$ & $\begin{array}{c}2^{\text {nd }} \text { loss } \\
(\%)\end{array}$ & $\mathrm{T}\left({ }^{\circ} \mathrm{C}\right)$ & $\begin{array}{c}3^{\text {rd }} \text { loss } \\
(\%)\end{array}$ & $\mathrm{T}\left({ }^{\circ} \mathrm{C}\right)$ & Residues \\
\hline $\mathrm{R} 1$ & $6.4 \pm 0.5$ & $61.5 \pm 2.6$ & $55.5 \pm 0.2$ & $\begin{array}{c}309.8 \pm \\
0.4\end{array}$ & $35.4 \pm 0.6$ & $\begin{array}{c}446.3 \pm \\
3.8\end{array}$ & $2.7 \pm 0.2$ \\
\hline R3 & $6.4 \pm 0.2$ & $57.6 \pm 1.9$ & $56.4 \pm 0.2$ & $\begin{array}{c}315.6 \pm \\
0.3\end{array}$ & $34.5 \pm 0.3$ & $\begin{array}{c}440.6 \pm \\
3.3\end{array}$ & $2.7 \pm 0.1$ \\
\hline $\mathrm{R} 6$ & $6.2 \pm 0.1$ & $56.8 \pm 2.4$ & $60.9 \pm 0.0$ & $\begin{array}{c}330.7 \pm \\
0.7\end{array}$ & $31.4 \pm 0.1$ & $\begin{array}{c}426.7 \pm \\
2.6\end{array}$ & $1.5 \pm 0$ \\
\hline
\end{tabular}

Table 5 Tensile properties of individual fibers for different retting times.

\begin{tabular}{cccccc}
\hline Batch & $\begin{array}{c}\text { Batch } \\
\text { diameter }(\mu \mathrm{m})\end{array}$ & $\begin{array}{c}\text { Tensile test } \\
\text { diameter }(\mu \mathrm{m})\end{array}$ & $\mathrm{E}(\mathrm{GPa})$ & $\sigma(\mathrm{MPa})$ & $\mathrm{A}(\%)$ \\
\hline R1 & $13.3 \pm 4.4$ & $14.0 \pm 2.7$ & $38.6 \pm 17.3$ & $792 \pm 374$ & $2.2 \pm 0.7$ \\
R3 & $13.0 \pm 4.0$ & $14.5 \pm 2.6$ & $48.6 \pm 11.8$ & $935 \pm 317$ & $2.2 \pm 0.7$ \\
R6 & $14.8 \pm 4.4$ & $15.9 \pm 2.5$ & $55.6 \pm 11.8$ & $1036 \pm 270$ & $1.9 \pm 0.5$ \\
\hline
\end{tabular}

Table 6 Tensile properties of previously dew-retted studied flax fibers.

\begin{tabular}{|c|c|c|c|c|c|}
\hline Variety & Reference & $\begin{array}{c}\text { Average } \\
\text { diameter }(\mu \mathrm{m})\end{array}$ & $\mathrm{E}(\mathrm{GPa})$ & $\sigma(\mathrm{MPa})$ & $A(\%)$ \\
\hline Ariane & (Baley, 2002) & $17.8 \pm 5.2$ & $54.1 \pm 15.1$ & $1339 \pm 486$ & $3.3 \pm 0.8$ \\
\hline Electra & $\begin{array}{l}\text { (Bourmaud et } \\
\text { al., 2010) }\end{array}$ & $15.4 \pm 4.9$ & $51.1 \pm 15.0$ & $808 \pm 342$ & $1.6 \pm 0.5$ \\
\hline Oliver & $\begin{array}{l}\text { (Bourmaud et } \\
\text { al., 2013b) }\end{array}$ & $17.5 \pm 3.6$ & $47.2 \pm 21.3$ & $751 \pm 414$ & $1.7 \pm 0.6$ \\
\hline Marylin & $\begin{array}{l}\text { (Bourmaud et } \\
\text { al., 2013a) }\end{array}$ & $15.85 \pm 3.9$ & $53.8 \pm 14.3$ & $1215 \pm 500$ & $2.2 \pm 0.6$ \\
\hline Alizée & $\begin{array}{l}\text { (Roussière et } \\
\text { al., 2012) }\end{array}$ & $15.20 \pm 3.3$ & $47.9 \pm 16,1$ & $1012 \pm 391$ & $2.3 \pm 0.7$ \\
\hline Oliver & $\begin{array}{c}\text { (Pillin et al., } \\
\text { 2011) }\end{array}$ & $15.3 \pm 4.5$ & $55.5 \pm 20.9$ & $899 \pm 461$ & $1.7 \pm 0.6$ \\
\hline
\end{tabular}


Table 7 Morphology of raw fibers, after compounding and after injection molding.

\begin{tabular}{cccc}
\hline Sample & Length $(\mu \mathrm{m})$ & Diameter $(\mu \mathrm{m})$ & Aspect ratio L/d \\
\hline \multicolumn{4}{c}{ Raw fibers } \\
\hline R1 & $3080 \pm 844$ & $175 \pm 131$ & $24 \pm 13$ \\
R3 & $3038 \pm 668$ & $172 \pm 128$ & $27 \pm 21$ \\
R6 & $3037 \pm 540$ & $192 \pm 134$ & $26 \pm 22$ \\
\hline \multicolumn{4}{c}{ After compounding } \\
R1 & $592 \pm 366$ & $74 \pm 46$ & $11 \pm 8$ \\
R3 & $513 \pm 280$ & $74 \pm 52$ & $10 \pm 7$ \\
R6 & $367 \pm 223$ & $34 \pm 27$ & $14 \pm 9$ \\
\hline \multicolumn{4}{c}{ After injection molding } \\
R1 & $351 \pm 188$ & $44.7 \pm 28.1$ & $10.7 \pm 8.1$ \\
R3 & $316 \pm 166$ & $36.7 \pm 25.5$ & $11.0 \pm 6.9$ \\
\hline
\end{tabular}

Table 8 Measured and predicted stiffness values.

\begin{tabular}{cccccc}
\hline Sample & E fibers (GPa) & L/D & $\begin{array}{c}\text { E composite } \\
(\mathrm{GPa}) \\
\text { Tests }\end{array}$ & $\begin{array}{c}\text { E composite } \\
(\mathrm{GPa}) \\
\text { Model }\end{array}$ & $\mathrm{V}_{\mathrm{f}}(\%)$ \\
\hline PP/MA-PP & $/$ & $/$ & $1.5 \pm 0.1$ & 1.5 & $/$ \\
R1 & $38.6 \pm 17.3$ & $10.7 \pm 8.1$ & $3.6 \pm 0.18$ & 3.5 & $18,9 \pm 0,05$ \\
R3 & $48.6 \pm 11.8$ & $11.0 \pm 6.9$ & $3.6 \pm 0.08$ & 3.7 & $19,5 \pm 1,6$ \\
R6 & $55.6 \pm 11.8$ & $13.5 \pm 7.0$ & $4.2 \pm 0.16$ & 4.0 & $20,3 \pm 0,06$ \\
\hline
\end{tabular}

\section{Figures}

Fig. 1. Rainfall, daily average temperature during the retting period and sample collection dates.

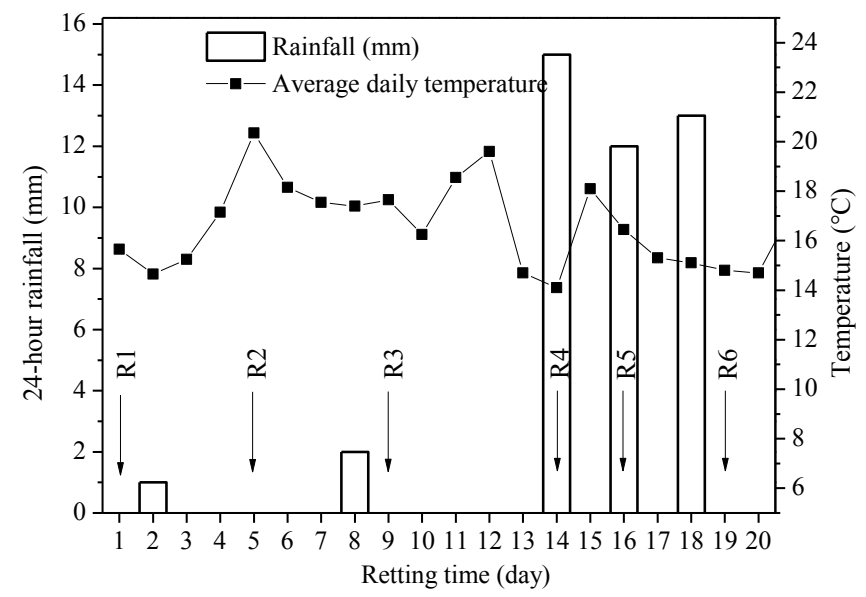


Fig. 2. Photograph of the raw fibers. From unretted fiber on the left to retted fiber on the right. Scale bar represents approximately $10 \mathrm{~cm}$.

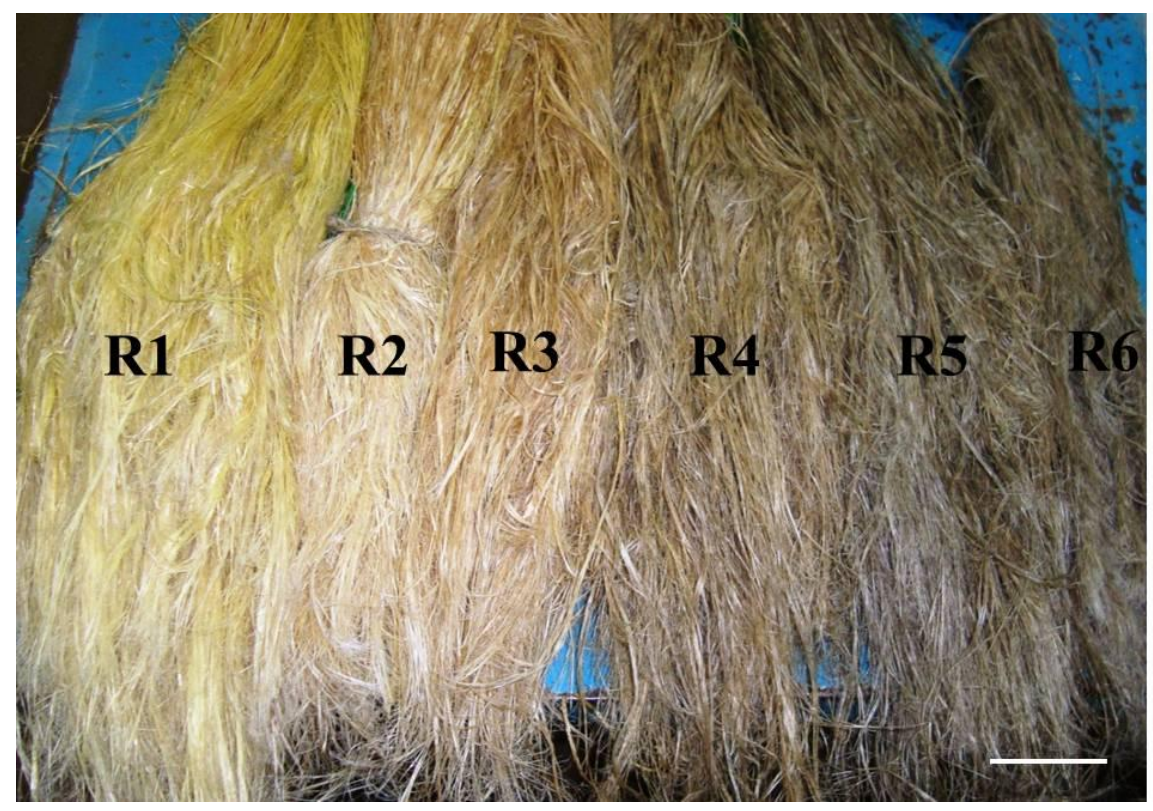

Fig. 3. (a) Schematic cross section of a flax stem. ( $\boldsymbol{\nabla} \nabla)$ Cuticle, ( $\boldsymbol{\nabla})$ Epidermis, (A) Cortical parenchyma, (B) Fiber bundles of the Phloem, (C) Core cells or Xylem. b) Schematic representation of a single flax fiber structure.

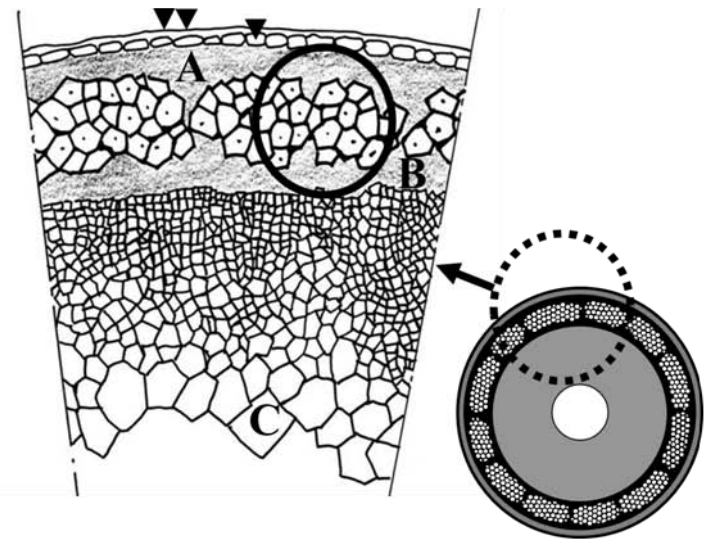

a)

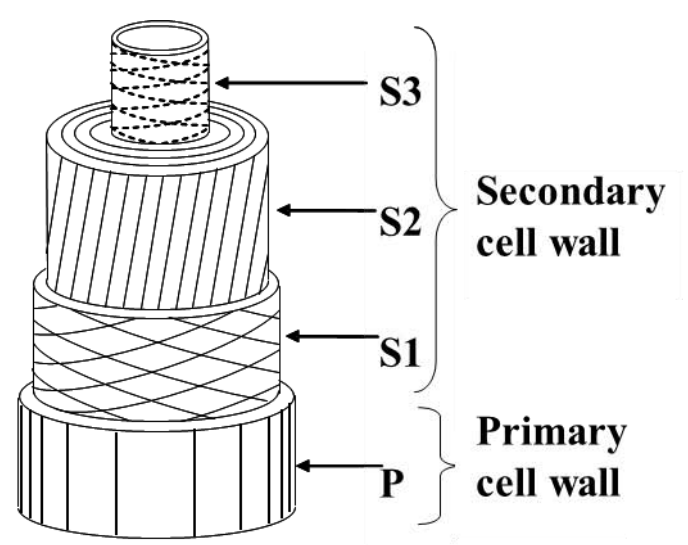

b) 
Fig. 4. Scanning electron microscopy pictures of $R 1$ fiber bundles (A) and (B), R3 fiber bundles (C) and (D), and R6 fiber bundles (E) and (F). The magnification is x500 on the left column and $\mathrm{x} 2000$ on the right column.
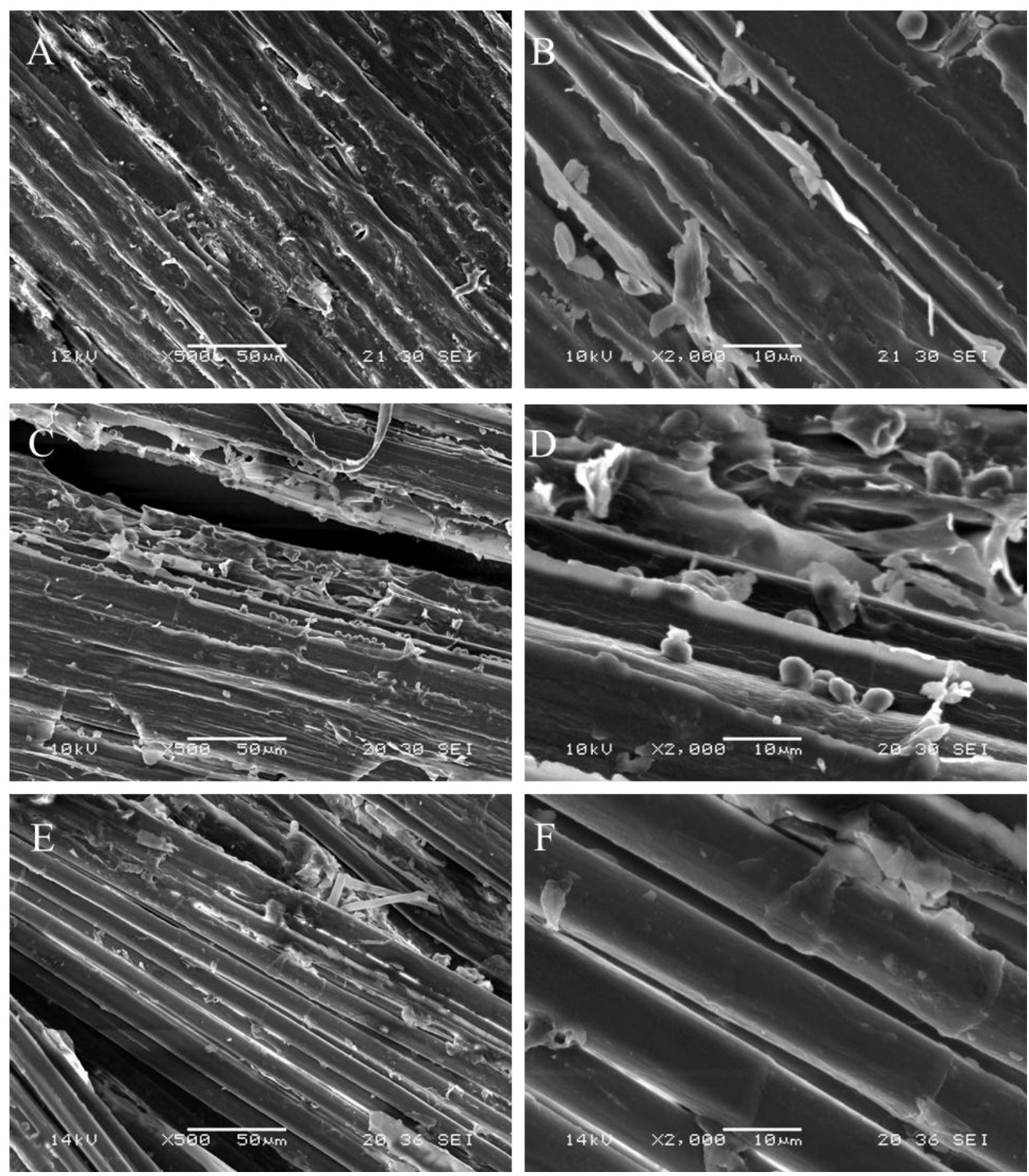
Fig. 5. Mass loss and derivative from the weight loss as a function of temperature.

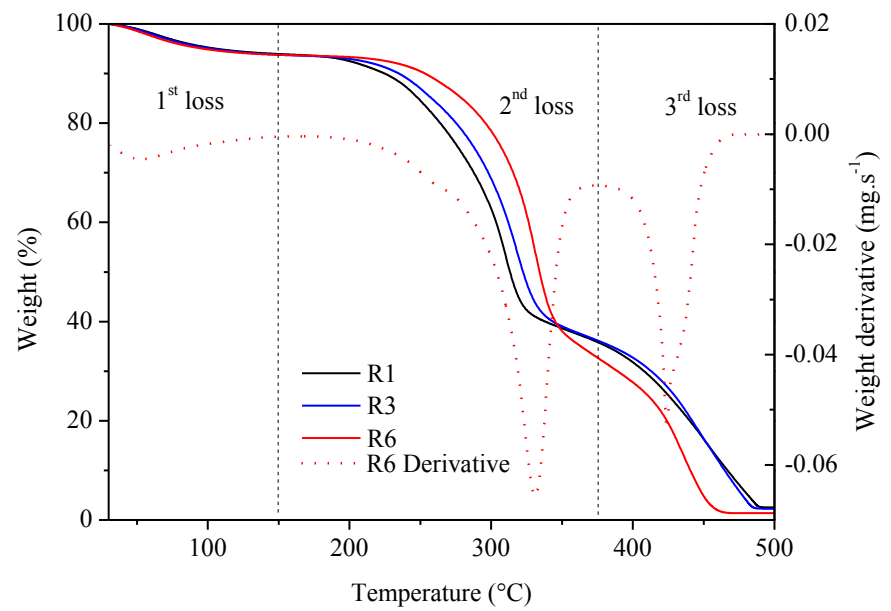

Fig. 6. Evolution of the water content as a function of relative humidity.

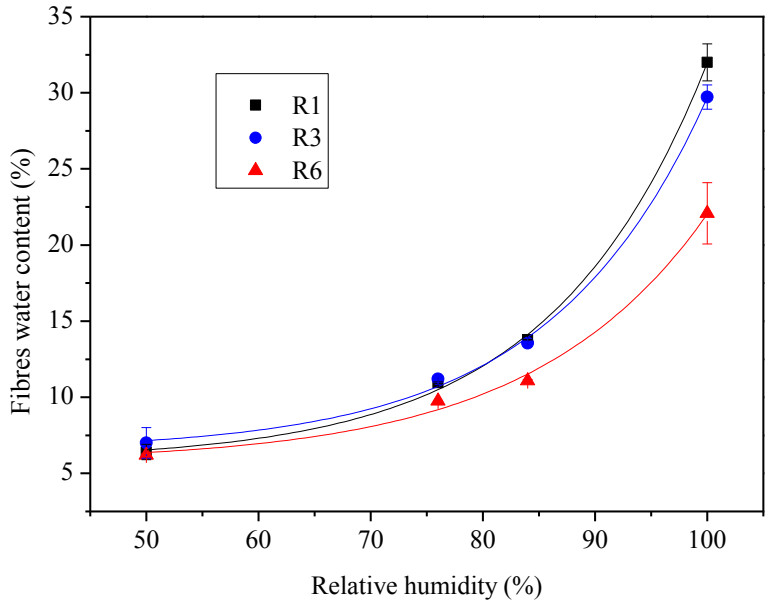


Fig. 7. (a) SEM pictures of R1 Core (A) and R1 Skin (B), R6 Core (C) and R6 Skin (D). (b) Schematic diagram of the tensile specimen highlighting SEM observation areas of skin and core. (c) 3D Diagram of fibre orientation at skin and at core in a tensile specimen, adapted from Bourmaud et al. (2013).

$\stackrel{\text { Flow direction }}{\longrightarrow}$
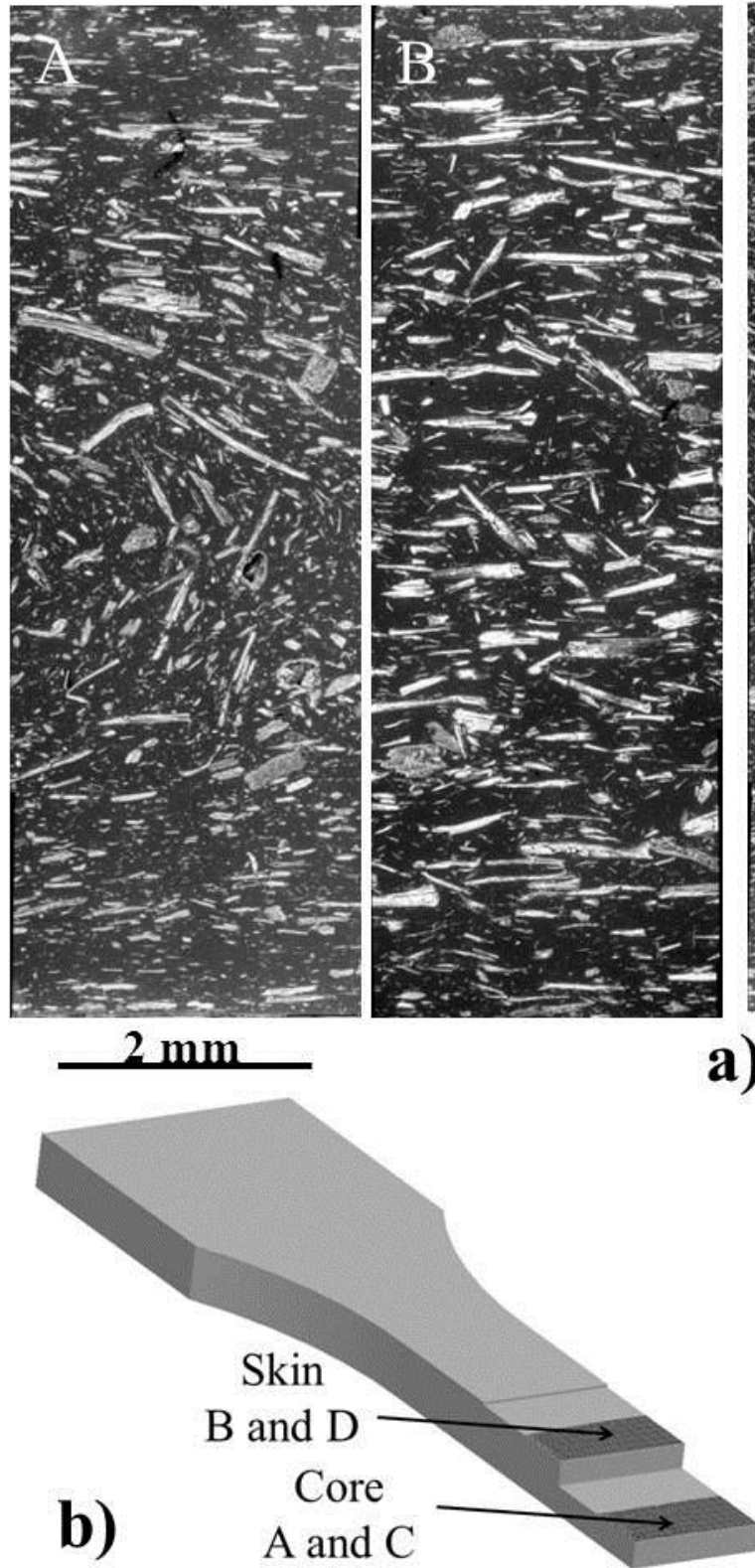

a)
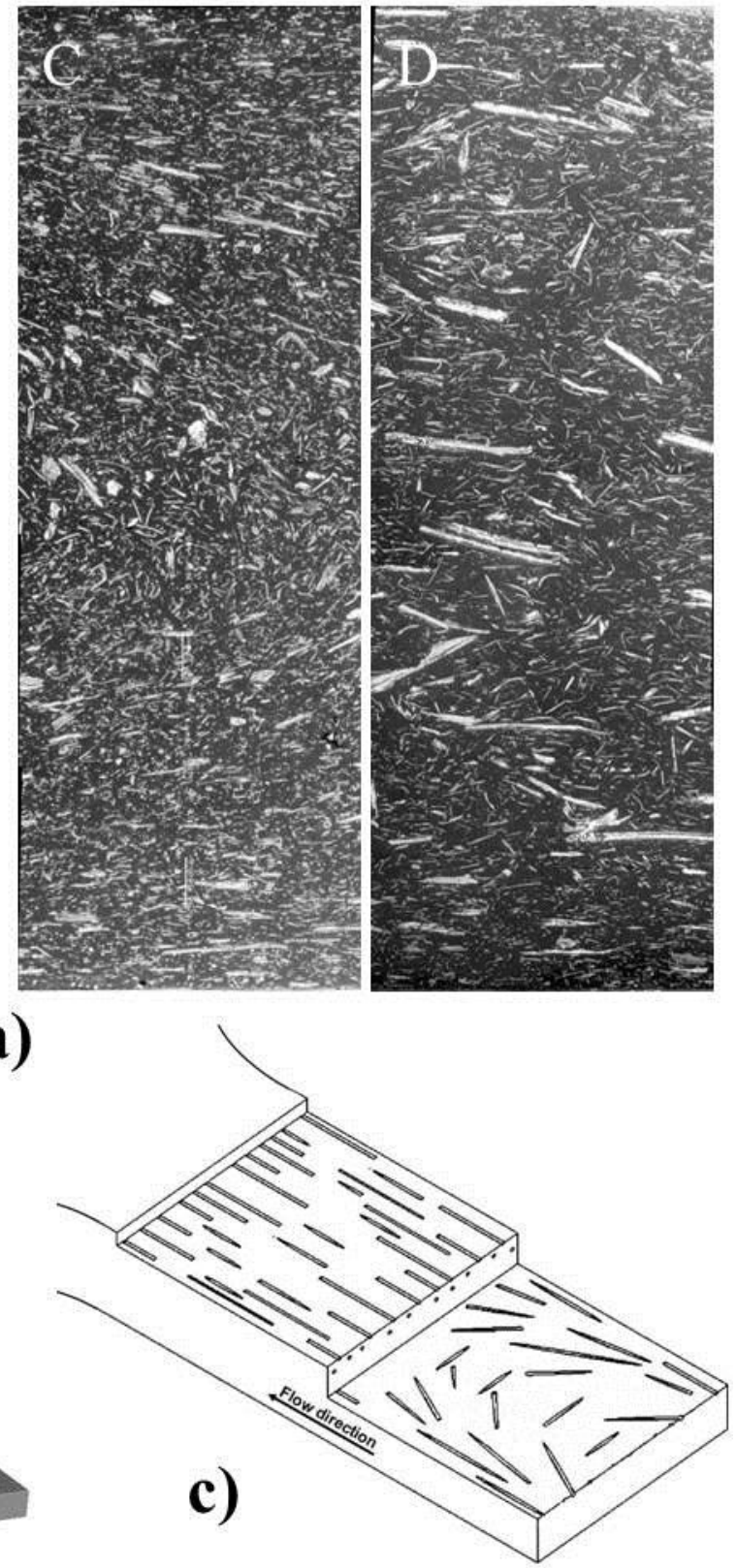
Fig. 8. Skin (A) and core (B) of PP/flax R6 sample extracted from X-ray micro tomography analysis of a tensile specimen. Scale bar represents $2 \mathrm{~mm}$.

Fig. 8. Skin (A) and core (B) of PP/flax R6 sample extracted from X-ray micro tomography analysis of a tensile specimen. Scale bar represents $2 \mathrm{~mm}$.

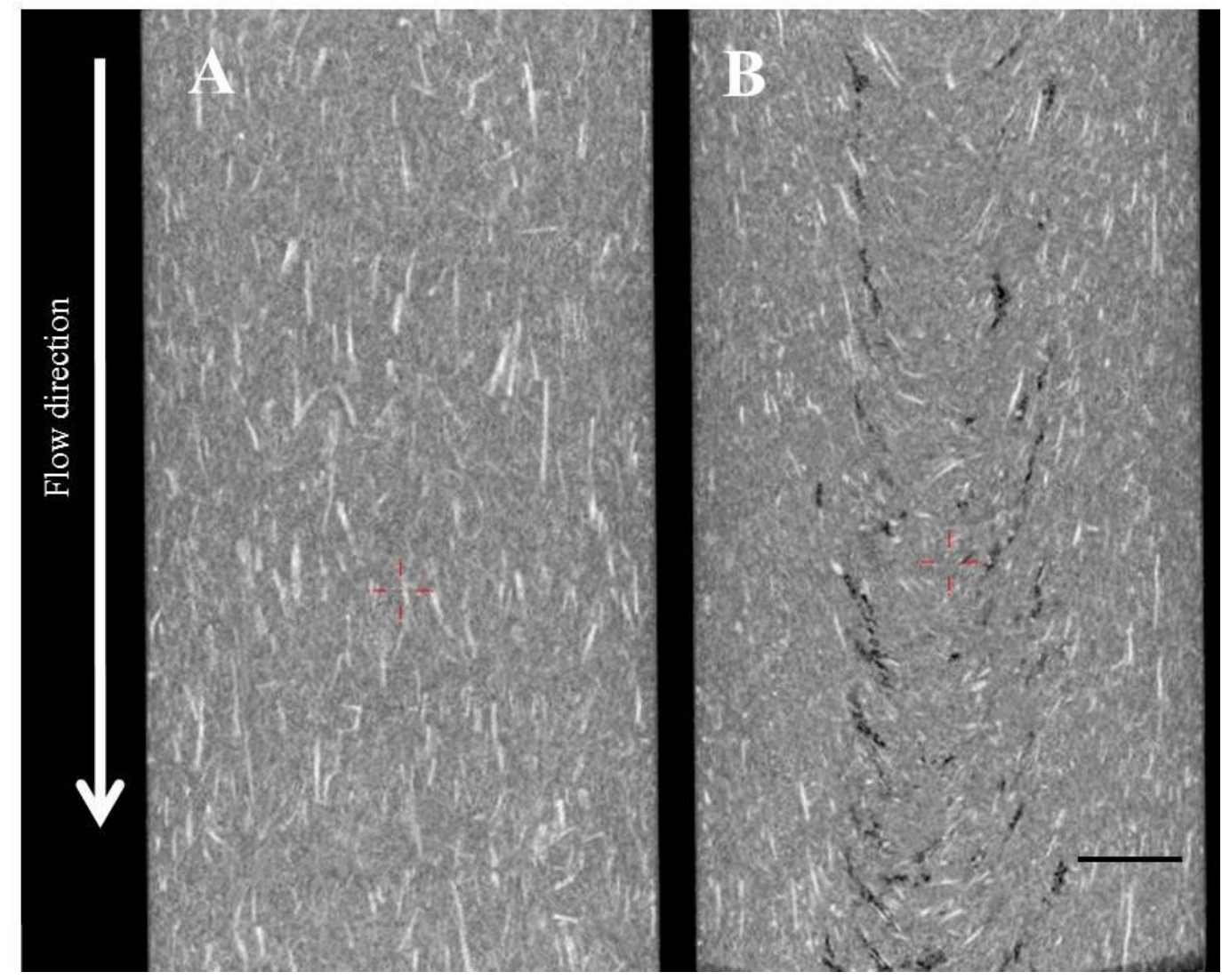


Fig. 9. 3 dimensional view of the $3 \mathrm{PP} /$ flax samples from X-ray micro tomography analysis highlighting the void content. From left to right: R1, R3 and R6. The smallest porosities are blue and the largest are red $\left(0,02\right.$ to $\left.0,18 \mathrm{~mm}^{3}\right)$.

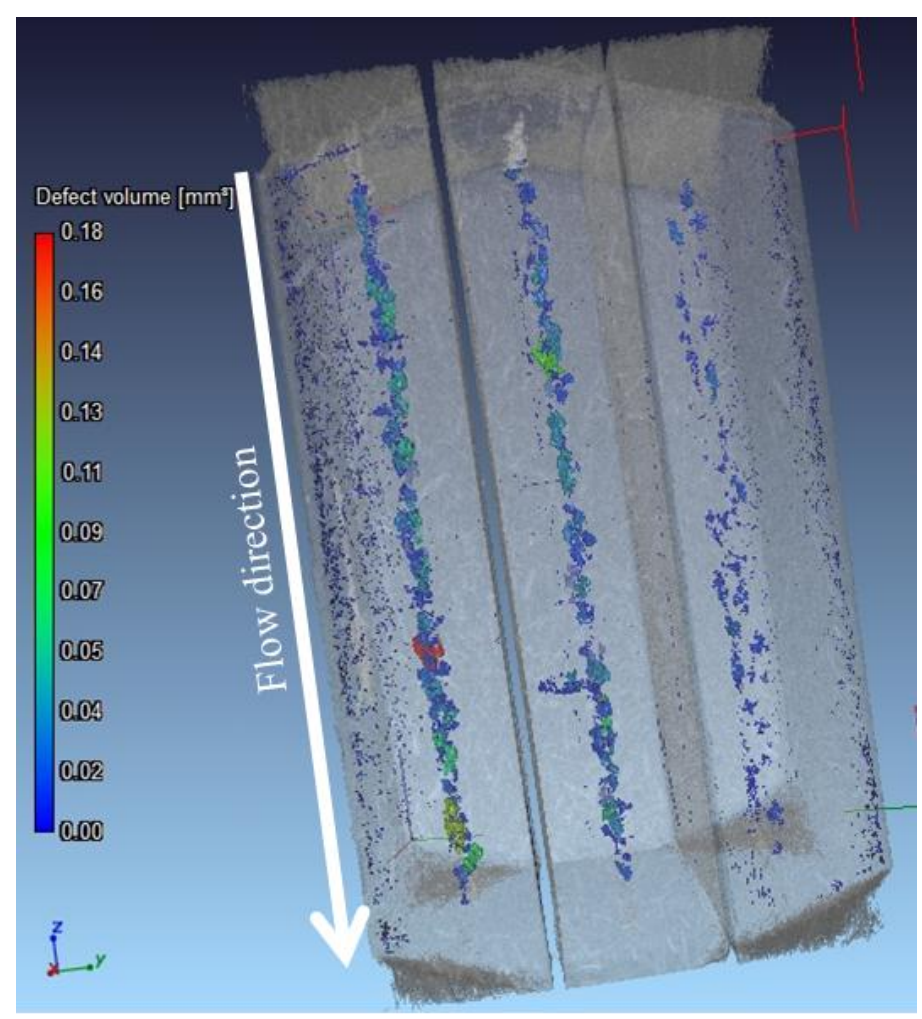

Fig. 10. Young's modulus, tensile strength, strain at break of composites.

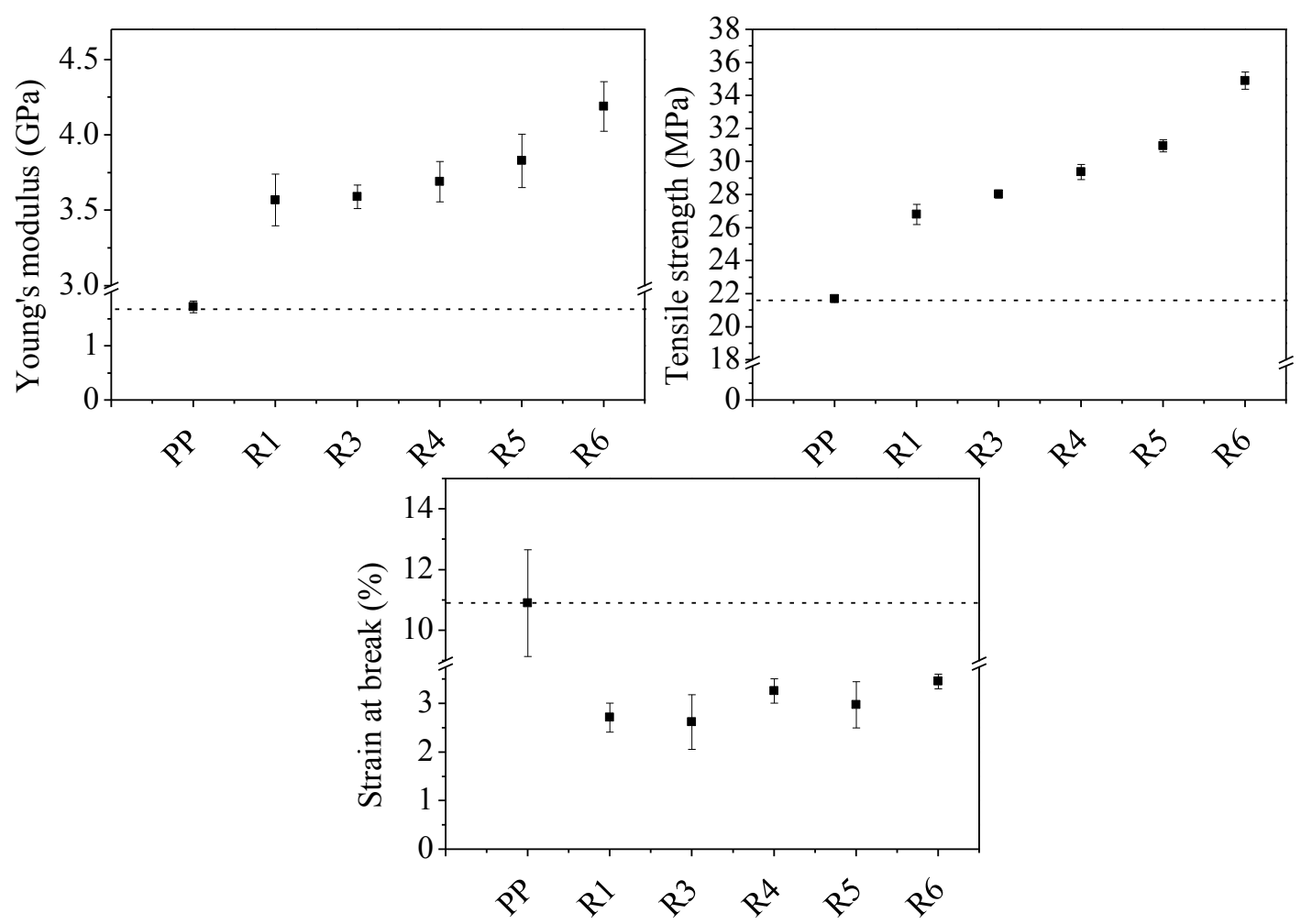

